\title{
EFFECTIVE INFORMATION TECHNOLOGY GOVERNANCE MECHANISMS: An Australian Study
}

\author{
SyaifulAli
}

Growing importance of information technology(IT), as a strategicfactorfor organizations in achieving their objectives, haveraised the concern of organizations in establishing and implementing effective IT governance. This study seeks to empirically examine the individual IT governance mechanisms that influence the overall effectiveness of IT governance.

The data were obtained by using web based survey from 176 members of ISACA (Information Systems and Audit Control Association) Australia. This study examines the influences of sixproposed IT governance mechanisms on the overall effectiveness of IT governance. Using Factor Analysis and Multiple Regression techniques, the current study finds significant positive relationships between the overall level of effective IT governance and the following four IT governance mechanisms: the existence of ethics/ culture of compliance in IT, corporate communication systems, an IT strategy committee, and the involvement of senior management in IT.

Keywords: Australia; Factor Analysis; ISACA; IT governance; mechanisms; web based survey 
Gadjah Mada International Journal of Business, January-April2006, Vol.8, No.1

\section{Introduction}

In recent years, information technology (IT) governance has been emerging as a central issue in the business and IT world. A survey conducted by Gartner (Top Ten CIO Management Priorities for 2003) revealed that "Improving IT governance" was ranked third by chief information officers (CIOs) (Grembergen and De Haes 2005). A more recent study, published in 2004 by the IT Governance Institute (2003b), entitled "IT Governance Global Status Report," "1 revealed that more than 80 percent of CIOs acknowledged the need for better IT governance in delivering their enterprises' strategies. Furthermore, the importance of IT governancewas supported by a study showing that firms with superior IT governance gained profits 25 percent higher than those with meagre governance, given similar strategic objectives (Weill and Ross 2004). According to the IT Governance Institute (2003a), IT governance is defined as: "A structure of relationships and processes to control the enterprise in order to achieve the enterprise's goals by adding value while balancing risk versus return over IT and its processes." 2
Despite the increasing importance of IT governance, evidence shows that many organizations have failed in their quest to obtain benefits from IT. Unsuccessful project development (e.g., being over budget and under specification), loss of competitiveness, and even organisational demise (Schwartz 2004; Woodhead 2004) have been attributed to lack of governance in IT.

Accordingly, effective IT governance is crucial for an organisation to achieve its corporate performance goals. To implement IT governance effectively, a set of IT governance mechanisms is required (e.g., IT steering committee, IT organisational structure) that encourages behaviors congruent with the organisation's mission, strategy, values, norms and culture (Vaswani 2003; Weill 2004).

Previous studies examining the effectiveness of IT governance mechanisms have indicated interesting results (Vaswani 2003; Well and Ross 2004). Vaswani (2003), whose respondents were 80 auditors in Queensland, Australia, found that certain individual mechanisms, such as an IT steering committee, involvement of senior management and corporate performance measurement systems, were correlated

\footnotetext{
${ }^{1}$ PriceWaterhouseCoopers $(\mathrm{PwC})$ conducted the survey for the IT Governance Institute. It involved $335 \mathrm{CEO} / \mathrm{CIO}-$ level respondents from all over the world.

${ }^{2}$ There are several other definitions of IT governance similar in effect to the study definition. Weill (2004, p.2) defined IT governance as "specifying the framework for decision rights and accountabilities to encourage desirable behavior in the use of IT." Van Grembergen (2004, p.5) defined IT governance as the "organisational capacity exercised by the Board, executive management, and IT management to control the formulation and implementation of IT strategy and in this way ensure the fusion of business and IT."
} 


\section{Ali-Effective Information Technology Governance Mechanisms}

positively with the overall level of IT governance effectiveness. Very recently, Weill and Ross (2004) surveyed CIOs from 256 enterprises in the US and identified fifteen of the most common IT governance mechanisms, such as a senior management committee, an IT executive committee, an architecture committee, etc. ${ }^{3}$ However, these studies did not provide a sufficient empirical data to support their findings. The present study addresses this shortcoming; it extends earlier studies by propose other mechanisms in IT Governance, and larger sample thus increasing the findings generalizability. Accordingly, the research question of this study is: what factors are required to establish and implement effective IT governance?

\section{Research Background}

Many studies have revealed the importance of IT governance. The study conducted by Weill (2004) of 116 profit-oriented firms has shown that effective IT governance indeed contributes a 20 percent higher return on assets (ROA), higher than for firms using the same strategy with less effective governance. Effective IT governance is critical, since IT investment tends to increase progressively. Gormolski et al. (2001) reveal that the average firm's IT investment was higher than 4.2 percent of annual revenues, which makes IT investment exceed 50 percent of the annual total investment of many firms. IT is also believed to influence almost all aspects of business, so budgeting for IT investment is difficult for many firms. Keen (cited in Devaraj and Kohli 2002), estimates that only 20 percent of IT expenditure is recognizable in the IT budget. Another reason for the importance of IT governance is that IT provides new business opportunities for firms. The rapid progress of new technologies, such as web-based services, mobile technology, and enterprise resource systems generate business opportunities as well as threats for firms (IT Governance Institute 2003a; Sampler and Weill 2003). Furthermore, the lack of effective IT governance has been shown to have adverse impacts on firms, such as business losses, bad reputation, 'runaway projects', and inefficient operational activities (Schwartz 2004; Woodhead 2004).

Given the increasing importance of controlling IT effectively, many researchers and practitioners have conducted intensive studies into the IT governance domain. Much of the literature in IT governanceacknowledges that, in order to implement IT governance effectively, a holistic approach needs to be adopted (e.g., Weill 2004). IT governance is complex and dynamic in nature; it consists of a set of interdependent subsystems (a mix of structures, processes and relational mechanisms) that work together as a whole

\footnotetext{
${ }^{3}$ For a more detailed discussion refer to: Weill and Ross (2004: 86-86).
} 
(Duffy 2002; Patel 2004; Peterson 2004; Sambamurthy and Zmud 1999; Weill and Ross 2004; De Haes and Grembergen 2005). This study, however, is limited to examining only the individual mechanisms.

To achieve effective IT governance, an organization needs to employ well-designed, well-understood, and transparent governance mechanisms (Weill and Ross 2004). However, good governance arrangements will fail to yield the expected results if mechanisms to support it are implemented inadequately. Weill and Ross (2004), surveyed CIOs of 256 firms from 23 countries, and identified fifteen of the most common IT governance mechanisms. Weill and Ross (2004) categorized these into three broad types in general: decision-making structures, alignment processes, and communication approaches. However this study did not try to test the fifteen mechanisms empirically in relation to the effectiveness of IT governance. In contrast, the present study seeks to provide empirical evidence of the correlation of some of these individual governance mechanisms with the overall level of IT governance effectiveness.

De Haes and Grembergen (2005) ran a case study in a major Belgian financial firm, examining how the mechanisms, processes and structures of IT governance contributed to the implementation of IT governance. The case study revealed that the firm used governance mechanisms effectively; for example, an executive committee composed of business and IT people, service-level agreements (SLAs), and charge-back systems were used to regulate IT resources.

Sohal and Fitzpatrick (2002) observed the IT governance mechanisms used by Australian organizations, including the existence of an IT steering committee, centralization of IT decision-making activities and the involvement of senior management in IT. However, the study did not provide empirical support of the relationship of the three mechanisms to the level of effectiveness of IT governance.

Recently, Vaswani (2003), using auditors in Queensland, ran a study to determine the effectiveness of IT governance mechanisms, revealing that the existence of three mechanisms an IT steering committee, the involvement of senior management in IT, and corporate performance measurement systems - were positively correlated with the effectiveness of IT governance. On the other hand, the other two mechanisms (centralisation of IT decision-making and the position of the IT function within the organization) were not supported. The study has, however, two shortcomings that this study intends to overcome. First, Vaswani's (2003) model only explained 52.3 percent of the variance of effective IT governance, implying other mechanisms not included in the model were also involved. Second, Vaswani's (2003) study used a relatively small sample size ( 80 auditors) and it only involved one ISACA Chap- 
Ali-Effective Information Technology Governance Mechanisms

ter (Queensland Chapter), thus limiting the external validity of the study's results.

\section{Researach Model and Hypotheses Development}

This study proposes to investigate the research model shown in Figure 1 . This study will test empirically the six IT governance mechanisms (IT strategy committee, IT steering committee, involvement of senior management in IT, corporate performancemeasurement systems, ethics/culture of compliance, and corporate communication systems).

As shown in Figure below, this study adopted and extended the prior study model (Vaswani 2003) into the following model:

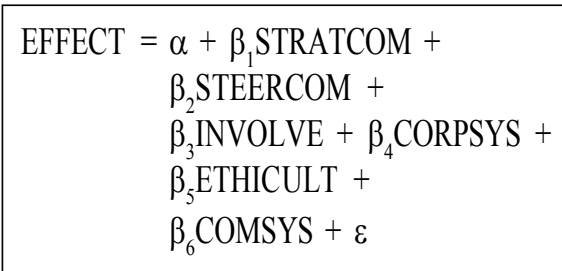

where:

EFFECT: Perceived overall effectiveness of IT governance;

STRATCOM: IT strategy committee; STEERCOM: IT steering committee; INVOLVE: Involvement of top management in IT;

CORPSYS: Corporate performance measurement systems;

ETHICULT: Ethics/culture of compliance;

COMSYS: Corporate communication systems.

\section{Figure 1. Research Model}

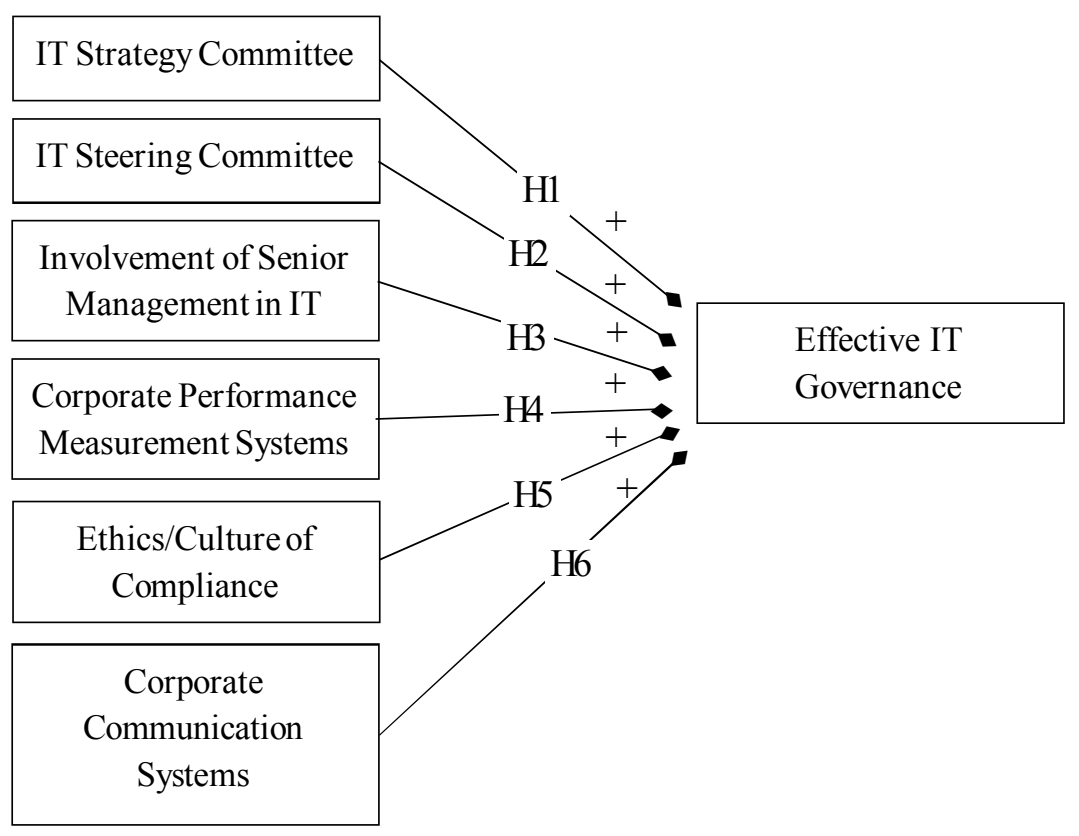


Gadjah Mada International Journal of Business, January-April 2006, Vol.8, No. 1

\section{IT Strategy Committee}

As IT becomes a critical element of business strategies or core operating processes, there is a need for greater involvement of the board of directors in establishing effective governance of IT. A board can pursue these responsibilities by establishing a committee called the IT strategy committee (IT Governance Institute 2003a). In this study an IT strategy committee means a sub committee of board members with responsibility to provide insight and advice to the board on topics such as the alignment of IT with the business direction and the achievement of strategic IT objectives; and also to provide direction to management relating to the IT strategy (IT Governance Institute 2003a).

The involvement of boards in IT governance implies that the organization is committed to establishing effective IT governance. The commitment of the IT strategy committee to IT governance is very important. Commitment is indicated by the provision of sufficient resources for meeting IT strategic objectives (Barlow 1990; Gottschalk 1996; Premkumar and King 1994), providing direction to management related to IT strategy and its approval (IT Governance Institute 2003a). Thus:

H1: The existence of an IT strategy committee will positively influence the effectiveness of IT governance.

\section{IT Steering Committee}

The IT steering committee, as a mechanism for supporting information systems planning and management, has been widely supported in the systems literature. In this study an IT steering committee means a high-level executive management team of representatives from multiple divisions or functions that are assigned the task of linking IT strategy with business strategy by setting strategic directions, matching corporate concerns with technology potential, and building commitment (IT Governance Institute 2003a). The committee serves as a high-level executive team, comprised of representatives from various divisions or functions within the organization (such as business executives and the CIO), with the main function of linking its IT strategy and business strategy (Nolan 1982; IT governance Institute2003a). Previous studies have empirically supported the benefits of the existence of an IT steering committee in IS planning and management (Doll 1985; Steiner 1979; Ragunathan and Ragunathan 1989).

Several earlier IS studies provide further empirical evidence of the importance of an IT steering committee. For example, a study by Karimi et al. (2000) found that an IT steering committee had a positive impact on the sophistication of IT management, and it was shown to have made improvements to IS project portfolios (McKeen 
and Guimaraes 1985). A more recent study by Vaswani (2003), using 80 auditors in Australia, revealed that an IT steering committee has a positive correlation with the level of effectiveness of overall IT governance. Thus:

H2: The existence of an IT steering committee will positively influence the effectiveness of IT governance.

\section{Involvement of Senior Management in IT}

Many researchers have examined the critical role of senior management practices in IS success. The involvement of senior management appears to lead to effective IS planning (Rockart 1988; Cerpa and Verner 1998; Earl 1993; Shuman and Rohrbaugh 1991; and Sohal and Fitzpatrick 2002). A lack of senior management involvement has been shown to lead to unfavorable outcomes in IS planning, and even failure to plan for IS. (Cerpa and Verner 1998; Nath 1989; Sabherwal 1999; and Salmela et al. 2000).

In the IT governance literature, a recent study by Vaswani (2003) has shown that senior management involvement was positively correlated with effective IT governance. Thus:

H3: Involvement of senior management in IT will positively influence the effectiveness of IT governance.

\section{Corporate Performance Measurement Systems}

One of the IT strategy committee's duties is to supervise the implementa- tion of its strategic agenda. To achieve this outcome, effective performance measurement mechanisms, such as an IT balanced scorecard, project tracking systems, and IT charge back systems, are necessary. Such a system enables the management and the board to detect and correct any deviations and alter the strategy when necessary (IT Governance Institute 2003a). In line with this argument, Hardy (2002) contends that the use of a performance management system is an integral part in applying effective IT governance. The measurement, which incorporates a set of metrics, provides management with a regular and precise analysis of how IT is performing the current operations and the latest projects. Thus: H4: The implementation of a corporate performance measurement system will positively influence the effectiveness of IT governance.

\section{Ethics/Culture of Compliance}

Over the last decade, business has been paying greater attention to corporate ethical and legal compliance programs. In a survey of Fortune 1000 firms, Weaver et al. (1990) found that 98 percent of responding firms address ethical or conduct issues in formal documents. Meanwhile, 78 percent have a separate code of ethics, and most of them distribute these policies widely within the organization. Recent corporate collapses, like Enron, WorldCom, HIH, and One.Tel, have shown that the lack of a culture of ethical compliance has adversely im- 
pacted the company's existence. This situation has forced government authorities to enact laws like the SarbanesOxley Act (2002) in US, and CLERP 9 in Australia, to address such cases in the future. In this study, ethics or culturerefers to similar concept that means "all the beliefs, values, attitudes, rituals and behavior patterns that people in an organization share" (Meyer 2004: 29).

Effective ethical compliance management has several advantages. First, as employees' ethical and legal awareness increase, the employees tend to ask questions correctly and, in the end, do the right thing when facing dilemmas. Second, it influences employees to be willing to report violations to management, thus contributing better decisions in the company. Finally, it increases employees' commitment, since a culture of ethical compliance creates value congruence that generates a sense of belongingness among employees (Trevino et al. 1999; McCabe et al. 1996).

In a similar vein, but with respect to IT governance, this study argues the need to promote a culture of ethical compliance in order for firms to achieve their IT governance effectively. Such an environment is useful in preventing and detecting conduct that may endanger the objectives of IT governance.

To achieve an effective ethics/ culture of compliance, a firm needs to establish a code of ethics, adopt and implement a comprehensive compliance program such as COSO (Committee of Sponsoring Organizations of the Treadway Commission), COBIT (Control Objectives for Information and related Technology), ITIL (Information Technology Infrastructure Library), and/or ISO 17799, provide sufficient ethical training for employees, and provide a reporting hotline. It is also important for top management to give leadership in promoting awareness of ethical compliance within their organization, as it sends messages to employees that inevitably shape the culture of their organizations (Beyer and Nino 1999). Thus:

H5: The existence of ethics/culture of compliance will positively influence the level of effective IT governance.

\section{Corporate Communication Systems}

The role of communication systems in the effective governance and management of IT has been examined extensively. Effective IT governance requires close relationships between the business and IT so that there will be better understanding between both areas, thus creating good participation and collaboration in the organization (Henderson et al. 1993; Broadbent 1998; Luftman and Brier 1999; Luftman 2000; Reich and Benbasat 2000; Callahan and Keyes 2004). Good communication systems will enable the two parties (business and IT) to increase each other's awareness of the importance of the other's perspective in obtaining benefits from IT (De Haes and Gremberge 2005). 
Ali-Effective Information Technology Governance Mechanisms

Communication mechanisms are also important for effective IT governance, as their purposes are to inform the organization as a whole about IT governance processes and decisions, and to encourage desirable behaviors in the organizations (Weill and Ross 2004). Furthermore, Weill and Ross (2004) reveal that some forms of communication mechanisms such as senior management announcements, and web-based portals contribute significantly to effective IT governance.

Weill and Ross (2004) also reveal that the more management communicate formally about the existence of IT governance mechanisms, how they work, and what outcomes are expected, the more effective are their governance processes. However, the study was based primarily on case studies that have a limitation in terms of external validity. By contrast, this study differs from the previous studies in that it provides empirical evidence of communication mechanisms based on an extensive questionnaire survey. Accordingly,

H6: The implementation of a corporate communication system will positively influence the effectiveness of IT governance.

\section{Research Methodology}

Data for this study were collected using web based survey. The online questionnaire survey was hosted on a server at the Business School at the University of Queensland. It was available on line from 23 April 2005 to 24
May 2005. Two rounds of pre-testing (initial testing and pilot testing) were conducted before the survey instrument was used for data collection purpose.

\section{Operational Measures of the Study Variables}

One important question in research design using factor analysis techniques is how to determine the number of variables to be included in the study. Hair et al. (1998) suggest that "the researcher should attempt to minimize the number of variables included but still maintain a reasonable number of variables per factor" (Hair et al. 1998: 98). In line with this suggestion, some methodologists have recommended that at least three to five measured variables representing each common factor be included in a study (MacCalum et al. 1999; Velicer and Fava 1998). With this in mind, the following variables were adopted from prior studies or newly developed for the purpose of this study. All the variables (dependent and independent variables) were measured using sevenpoint Likert scales. The complete results of factor analysis are exhibited in Appendix B.

Dependent variables. Perceived overall level of effective IT governance (EFFECT) was measured using two items that were validated by Vaswani (2003). The two items were originally developed and validated in Goodhue and Thompson (1995) (see Appendix A). 
Gadjah Mada International Journal of Business, January-April 2006, Vol.8, No. 1

Independent variables. To measure IT Strategy Committee (STRACOM), three questions adapted from the IT Governance Institute (2003a) were used (see Appendix A).

IT Steering Committee (STEER $\mathrm{COM}$ ) was measured using three items that werevalidated by Vaswani(2003). All three items were originally developed and validated based on a study conducted by Karimi et al. (2000) (see Appendix A).

To measure involvement of top management in IT (INVOLVE), this study used three items that were validated by Vaswani (2003). The first two items were originally developed and validated based on a study conducted by Jarvenpaa and Ives (1991); while the last item was developed and validated by Vaswani (2003) (see Appendix A).

Corporateperformancemeasurement system (CORPSYS) was measured using three items that were validated by Vaswani (2003). All three items were originally developed and validated based on a study conducted by Chan and Ho (2000) (see Appendix A).

To measure ethics/culture of compliance(ETHICULT), three items from Trevino et. al., (1999) were adapted to the context of IT governance (see Appendix A).

Corporate communication systems (CORPSYS) was measured using three items adapted from Weill and Ross (2004) (see Appendix A).

\section{Reliability of the Measures}

Reliability assessment was carried out using Cronbach's alpha, in order to ensure that the variables comprising each proposed research construct were internally consistent. Reliability concerns the extent to which measurements are repeatable when different persons make the measurements on different occasions (Nunnally 1978). The coefficient alpha is the statistic for determining reliability based on internal consistency. Its value ranges from 0 to 1 , with values of 0.60

Table 1. Variable Characteristics

\begin{tabular}{lc}
\hline \multicolumn{1}{c}{ Variables } & Reliability* \\
Overall effectiveness of IT governance & 0.9815 \\
IT strategy committee & 0.9305 \\
IT steering committee & 0.8793 \\
Involvement of top management in IT & 0.9312 \\
Corporate performance measurement system & 0.9261 \\
Ethics/Culture of compliance & 0.9366 \\
Corporate communication systems & 0.9618 \\
\hline
\end{tabular}

*Reliability measure is Cronbach's Alpha 
to 0.70 considered the lowest acceptable limit for reliability (Hair et al. 1998). This study adopts the same criteria for determining construct reliability. Based on the data from pilot testing of the survey instrument, Table 1 below shows that the reliability estimates (Cronbach's alpha) of the measures of the planned variables are well above acceptable thresholds.

\section{Results and Discussion}

\section{Response Rate}

Email invitations to participate in the survey were sent out to $1116 \mathrm{mem}$ bers of ISACA throughout Australia (to the Brisbane, New South Wales, Canberra, Melbourne, Adelaide and
Perth Chapters). The total of completed and usable responses was 176 , thus the response rate for this survey is 15.77 percent. This response rate is relatively high compared with previous similar studies (Vaswani 2003; Sohal and Ng 1998.

\section{Sample Characteristics}

In regard to the audit background of the respondents, the present study reveals that there are 122 internal auditors (69 percent) and 54 external auditors (30.7 percent). The data indicates that 79 percent (of which 86 of them are CISA qualified) of the current study's respondents identified themselves as IS auditors. The mean audit experience is 9.30 years with the

\section{Table 2. Sample Characteristics}

\begin{tabular}{|c|c|c|c|}
\hline & & Frequency & Percentage \\
\hline \multirow[t]{3}{*}{ A. } & Audit background $(\mathrm{n}=176)$ & & \\
\hline & Internal auditor & 122 & $69 \%$ \\
\hline & External auditor & 54 & $31 \%$ \\
\hline B. & IS Auditor & 139 & $79 \%$ \\
\hline \multirow[t]{2}{*}{ C. } & $\begin{array}{l}\text { Qualified CISA (certified information } \\
\text { systems auditor) }\end{array}$ & 86 & $49 \%$ \\
\hline & Experience and Familiarity* & Mean & Std. Dev. \\
\hline D. & Audit experience (years) & 9.30 & 7.46 \\
\hline E. & IS Audit experience (years) & 7.85 & 6.21 \\
\hline F. & $\begin{array}{l}\text { Familiarity with IT Governance } \\
\text { Type of Industry }\end{array}$ & 5.69 & 1.23 \\
\hline D. & Government & & 26 \\
\hline E. & Finance, Banking and Insurance & & 18 \\
\hline & Chartered Firm/Management Consulting & & 13 \\
\hline & Others & & 43 \\
\hline
\end{tabular}

* On a 7-point Likert scale: (1= Not at All; 7= a Great Extent $)$ 
IS audit experience 7.85 years. The familiarity with IT governance implementation (or concepts), reported in this study result is moderately high with value of 5.69 (on a 7-point scale).

The sample data covered a range of industry types. For the three top list are: government agencies (26 percent), Finance, Banking and Insurance (18 percent) and Chartered Firm/Management Consulting (13 percent). The study's data shows that 44 percent of the organizations had annual IT budgets more than $\$ 10$ millions, 5-10 millions (13 percent), 1-5 millions (19.8 percent), $\$ 200 \mathrm{~K}-1$ million (13.6 percent ) and Less than $\$ 200 \mathrm{~K}(0.1$ percent ).

\section{Data Examinations}

The sample data must satisfy some statistical assumptions underlying the multiple regression method, such as linearity, normality, homoscedasticity, and independence of residuals. Other assumptions are multicollinearity, and absence of outliers. Departures from these assumptions may affect the accuracy of the results (Hair et al. 1998).

Linearity and Normality. Multiple regressions assume that the relationship between the dependent and independent variables is linear (Hair et al. 1998). Significant violation of linearity means regression results may be more or less unusable. An examination of scatter plots revealed no serious violation of this assumption. It is also assumed in multiple regression that the residuals are distributed nor- mally (i.e., follow the normal distribution) around each and every predicted score of the dependent variable (Tabachnick and Fidell 1996). An inspection of the normal probability plots of the residuals and the scatter plot of residuals against predicted values confirmed that there was no departure from the assumption.

Homoscedasticity and independence of the error terms. Homoscedasticity means that the variance of errors is the same across all levels of the independent variables (Hair et al. 1998). Departures from the assumption, (i.e., the variance of errors differs at different values of the independent variables) will lead to heteroscedasticity. Visual examination of the residual scatter plots revealed no evidence of such violation. Independence of the error assumes that each predicted value is independent of any other prediction (Hair et al. 1998). Departures from the assumption will lead to autocorrelation that will subsequently lead to inefficient prediction. An examination of the residual plot revealed no evidence of such violation.

Multicollinearity and outliers. One common problem that exists when applying multiple regression using more than five independent variables is that two or more of them may be highly correlated to one another, a condition called multicollinearity (Tabachnick and Fidell 1996). Gujarati (1999) suggests that any correlations greater than 0.8 may imply the existence of multicollinearity problems. An 


\section{Ali-Effective Information Technology Governance Mechanisms}

inspection of the Pearson correlation matrix revealed that the highest correlation that exists is that between COMSYS and ETHICUL (0.708), which indicates that the variables are reasonably free of the problem. Data screening of the sample data was undertaken in order to identify any outliers (univariate and multivariate outliers). ${ }^{4}$ There are no outliers identified following this process.

In addition, Hair et al. (1998) suggest that a general rule in determining the sample size for a multiple regression is that the ratio of cases to the number of independent variables should not be less than five to one. A level between fifteen and twenty cases per independent variable is highly preferable. The risk of 'over fitting' will exist when the sample size for multiple regression is less than this requirement, making the results only apply to the specific data (Hair et al. 1998), thus reducing the generalizability of the results. Given the sample in the present study has 176 observations (with seven independent variables); the usage of the multiple regression technique was deemed appropriate.

\section{Results}

Table 3 presents the mean and standard deviation for variables in-

Table 3. Descriptive Statistics: Multiple Regressions

\begin{tabular}{lccc}
\hline \multicolumn{1}{c}{ Variable } & Mean & Std. Deviation \\
STRACOM & & 4.6576 & 1.68956 \\
STERCOM & & 4.6787 & 1.53730 \\
INVOLVE & 4.7141 & 1.43013 \\
CORPSYS & 3.9016 & 1.55175 \\
ETHICUL & 4.4801 & 1.45441 \\
COMSYS & 4.3582 & 1.52147 \\
EFFECT & 4.1676 & 1.44183 \\
\hline
\end{tabular}

Table 4. Model Summary of Multiple Regressions

\begin{tabular}{|c|c|c|c|c|c|}
\hline Model & R-Square & $\begin{array}{l}\text { Adjusted } \\
\text { R Square }\end{array}$ & F-statistics & Sig. F & Durbin-Watson \\
\hline 1 & 0.715 & 0.703 & 57.791 & 0.000 & 1.977 \\
\hline
\end{tabular}

Predictors: (Constant), COMSYS, STRACOM, INVOLVE, STERCOM, CORPSYS, ETHICUL Dependent Variable: EFFECT

\footnotetext{
${ }^{4}$ Outliers were identified by inspection. The Z-scores that were greater than +3 and less than -3 were considered to be outliers (Coakes and Steed 2003).
} 
cluded in the multiple regression analysis.

Table 4 presents the results of multiple regressions using SPSS. The table indicates that all independent variables explain 71.5 percent of the variance in the overall effectiveness of IT governance. This value is highly significant as indicated by the F-value and the significance (F-statistics $=57.791, \mathrm{p}=000$ ). This study's $\mathrm{R}^{2}$ is relatively high compared with the previous study by Vaswani (2003) that had an $\mathrm{R}^{2}$ of 56.6 percent.

Table 5 presents the results of the multiple regression analysis that reveals the significance of the hypotheses. IT strategy committee had a significant and positive effect on the effectiveness of IT governance $(\rho=$ 0.049 ), that suggests some support for Hypothesis 1 - the existence of IT strategy committees positively influences the effectiveness of IT governance.
This empirical finding partially supports the normative literature proposed by the IT Governance Institute (2003a). As those at board level get involved in the governance of IT through an IT strategy committee, they can provide influential advice to the board and management on recent and future ITrelated issues and their alignment with business.

Conversely, Hypothesis 2 (IT steering committee) had a marginally significant $(\rho=0.094)$ effect on the effectiveness of IT governance, at a 0.10 acceptance level. Surprisingly, the result reveals that this significance was negative, which is inconsistent with previous studies (Vaswani 2003; Karimi et al. 2000), which found the IT steering committee positively influenced the level of effective IT governance. A possible explanation of this finding could be the way in which the related survey items were worded, so

Table 5. Results of Regression

\begin{tabular}{|c|c|c|c|c|c|}
\hline \multirow[t]{2}{*}{ Variable } & \multicolumn{2}{|c|}{$\begin{array}{l}\text { Unstandardized } \\
\text { Coefficients }\end{array}$} & \multirow{2}{*}{$\begin{array}{c}\begin{array}{c}\text { Unstandardized } \\
\text { Coefficients }\end{array} \\
\text { Beta }\end{array}$} & \multirow[t]{2}{*}{ t-statistic } & \multirow[t]{2}{*}{ Sig. (2-tailed) } \\
\hline & B & Std. Error & & & \\
\hline (Constant) & .090 & 0.271 & & 0.333 & 0.740 \\
\hline STRACOM & .099 & 0.050 & 0.117 & 1.989 & $0.049 * *$ \\
\hline STERCOM & -.108 & 0.064 & -0.111 & -1.686 & $0.094 *$ \\
\hline INVOLVE & 0.113 & 0.064 & 0.108 & 1.755 & $0.082 *$ \\
\hline CORPSYS & -.048 & 0.062 & -0.050 & -0.773 & 0.441 \\
\hline ETHICUL & .382 & 0.070 & 0.378 & 5.418 & $0.000 * * *$ \\
\hline COMSYS & .478 & 0.067 & 0.506 & 7.188 & $0.000 * * *$ \\
\hline $\begin{array}{l}\text { * Significant at } \\
{ }^{* *} \text { Significant } \\
\text { ** Significant }\end{array}$ & $\begin{array}{l}\text { the } 0.1 \mathrm{le} \\
\text { th the } 0.05 \\
\text { at the } 0.0\end{array}$ & $\begin{array}{l}\text { vel (2-tailed) } \\
\text { level (2-tailed) } \\
1 \text { level (2-tailed }\end{array}$ & & & \\
\hline
\end{tabular}




\section{Ali-Effective Information Technology Governance Mechanisms}

that the respondents had mixed perceptions or saw an ambiguity with hypotheses 1 (IT Strategy Committee). Another possible explanation is that, for these organizations, other mechanisms such as IT strategy committee and involvement of senior management in IT were perceived as more effective in influencing the overall level of effective IT governance. This was indicated by the significance level of the two mechanisms (IT strategy committee and involvement of senior management in IT) being higher relative to that of the IT steering committee.

A positive and marginally significant result ( $\rho=0.082)$ was also found for Hypothesis 3. This finding suggests that the involvement of senior management is a positively influence on the effectiveness of IT governance, consistent with the previous study by Vaswani (2003). As previous literature sources reveal, the importance of senior involvement in IT has several benefits, such as leading to effective IS planning (Cerpa and Verner 1998; Earl 1993; and Sohal and Fitzpatrick 2002). On the other hand, a lack of senior management involvement has been shown to lead to unfavorable outcomes in IS planning and even to failure to plan for IS (Sabherwal 1999; and Salmela et al. 2000).

Interestingly, the results provide no support for Hypothesis 4 that pro- poses corporate performance systems positively influence the effectiveness of IT governance. The results reveals that the variable has a negative and non-significant result $(\rho=0.441)$. The result is inconsistent with previous study by Vaswani (2003), which found a positive correlation between this variable and the overall effectiveness of IT governance. The possible explanation of this finding is that the respondents to this study had mixed perceptions of the type of corporate performance measurement systems in use. The previous study by Vaswani (2003) used only the balanced IT scorecard as a proxy for corporate performance measurement systems whereas the present study used other measurement systems (including the balanced IT scorecard) such as project tracking systems and IT chargeback systems (e.g., Weill and Ross 2004). Another possible explanation may be that the concept of the balanced IT scorecard is relatively new and merely supported by the theoretical approaches of Van Grembergen and Van Bruggen (1997) and Van Der Zee and De Jong (1999). There were not many organizations that really practise the IT balanced scorecard performance measurement system ${ }^{5}$.

Ethics/Culture of compliance in IT had a highly significant and positive influence on the overall effectiveness of IT governance $(\rho<0.01)$. This

\footnotetext{
${ }^{5}$ Even the adopters world-wide of 'conventional' balanced scorecard, based on Kaplan's concept (1992) are limited. According to a database of balanced scorecard adopters worldwide, there is only one organization in Australia that claimed to apply the balanced scorecard as its corporate performance measurement systems (http:www.balancedscorecard.org/).
} 
result provides support for Hypothesis 5 that the existence of Ethics/Culture of compliance influences a perception of an effective level of IT governance. This finding provides the first empirical support of the benefits of Ethics/ Culture of compliance in the IT governance literature. This finding is similar to other findings in the ethics literature, that reveals the increase of ethical and legal awareness of employees leads them to 'do the right thing' when facing dilemmas. It influences the employees to be willing to report violations to management, thus contributing to better decisions in the company. Lastly, it increases employees' commitment as an ethics/culture of compliance creates value congruence that generates a sense of belongingness among employees (Trevino et al. 1999; McCabe et al. 1996). These kinds of environments are useful in preventing and detecting conduct that may endanger the objectives of IT governance.

The corporate communication systems were also found to have a positive and significant effect $(\rho<0.01)$, supporting hypothesis 6 that the existence of corporate communication mechanisms relate positively to the overall effective level of IT governance. Corporate communication systems contribute the most influence $(\beta=0.480)$ toward the overall effectiveness of IT governance. Despite many studies revealing similar findings (Henderson et al. 1993; Broadbent and Weill 1998; Luftman and Brier 1999; Luftman 2000; Reich and Benbasat 2000; Callahan and Keyes
2004) this study provides the first empirical evidence based on an extensive survey in the context of the importance of corporate communication systems to IT governance.

\section{Summary, Contribution, Limitation, and Future Study}

\section{Summary}

This study sought to examine empirically the individual IT governance mechanisms that influence the overall effectiveness of IT governance. Obtaining the sample data by surveying 1116 members of ISACA (Information Systems Audit and Control Association) throughout Australia, with a 15.77 percent response rate, this study examined the influences of the following IT governance mechanisms on the overall effectiveness of IT governance: IT strategy committee, IT steering committee, involvement of senior management in IT, corporate performance measurement systems, ethics/culture of compliance in IT, and corporate communication systems.

This study advances our understanding of the roles of IT governance mechanisms and their impact on the overall effectiveness of IT governance. In particular, this study found robust empirical evidence that (1) the existence of ethics and a culture of compliance in IT is positively correlated with the overall effectiveness of IT governance, (2) the existence of corporate communication systems support greatly enhances the overall effective- 


\section{Ali-Effective Information Technology Governance Mechanisms}

ness of IT governance, and (3) the existence of IT strategy committee is positively correlated with the overall effectiveness of IT governance.

Moreover, the findings suggest that the involvement of senior management in IT, are positively influences on the overall effectiveness of IT governance. Though, caution should be applied when interpreting these results as the study found only marginally significant support (at a ten percent acceptance level) for the related mechanisms.

\section{Contributions}

The study's findings contribute to both theoretical and practical aspects of IT governance. In terms of theoretical contributions, this study, which modify and extend an earlier study by Vaswani (2003) examined other additional individual IT governance mechanisms (IT strategy committee, ethics/ culture of compliance in IT and corporate communication systems) and their influences on the overall effectiveness of IT governance. The findings of this study provide empirical results on the IT governance mechanisms that have been previously studied mainly by normative and case study approaches (IT Government Institute 2003; Weill and Ross 2004).

Calling on the ethics and organizational literature (Trevino et al. 1999; McCabe et al. 1996), this study is the first empirical study to examine the influence of ethics/culture of compliance in the context of IT governance. This finding contributes to IT gover- nance literature evidence of the importance of ethics/culture of compliance in establishing effective IT governance.

In regard to practical contributions, there are some practical conclusions from the study findings that can be applied in establishing and implementing IT governance effectively. The findings suggest that the most influential mechanisms for increasing the overall effectiveness of IT governance are the existence of an ethic and/or culture of compliance in IT and the support of corporate communication systems, such as a web portal, in disseminating information related to IT governance activities. Other mechanisms also proved to make a marginal impact on the overall effectiveness of IT governance, such as an IT strategy committee and the involvement of senior management in IT. Finally, the results also can be used by organisations as empirical evidence against which to benchmark their own IT governance practices.

\section{Limitations and Recommendations for Future Study}

As for every other piece of research, this study also has some limitations that should be considered when interpreting its findings. The limitations also serve as references for performing future research.

First, more reliable measures of the overall effectiveness of IT governance in an organizations need to be developed, since subjective and indirect measures (based on auditor's per- 
Gadjah Mada International Journal of Business, January-April2006, Vol.8, No.1

ceptions) do not provide the same strength as direct objective measures would. This limitation was similar to that of an earlier study (Vaswani 2003) and was deemed unavoidable, as the type of research methodology used was a questionnaire approach, in the absence of objective measures.

Second, as IT governance is complex and dynamic in nature, consisting of a set of interdependent subsystems (a mix of structures, process and relational mechanisms) that work together as a whole (Peterson 2004; Sambamurthy and Zmud 1999; Weill and Ross 2004; De Haes and Grembergen 2005), the existence of the IT governance mechanisms does not necessarily guarantee that effective IT governance can be attained within the organisation. Later researchers need to study other requirements (i.e., structures and process) that support effective IT governance and its relation with IT governance mechanisms.

\section{References}

Armstrong, J. S., and T.S. Overton. 1977. Estimating nonresponse bias in mail surveys. Journal of Marketing Research 14: 396-402.

Barlow, J. F. 1990. Putting information systems planning methodologies into perspective. Journal of Systems Management 41 (7): 6-15.

Beyer, J. M., and D. Nino. 1999. Ethics and cultures in international business. Journal of Management Inquiry 8 (3): 287-297.

Broadbent, M. 1998. Leading Governance, Business and IT Processes: The Organisational Fabric of Business and IT Partnership. Finding Gartner Group.

Callahan, J., and D. Keyes. 2004. The evolution of IT Governance@ NB Power. In Grembergen (Ed.), Strategies for Information Technology Governance: Idea Group Publishing.

Cerpa, N., and J. M. Verner. 1998. Case study: The effect of IS maturity on information systems strategic planning. Information and Management 34: 199-208.

Chan, Y-C. L., and S-J. K Ho. 2000. The use of balanced scorecard in Canadian Hospitals. http://aaahq.org/NERegion/2000/q.17.pdf(Visited 1 February 2005).

Clarkson, P., C. Ferguson, and J. Hall. 2003. Auditor conservatism and voluntary disclosure: Evidence from the year 2000 systems issues. Accounting and Finance 43: 21-40.

Cook, T. D., and D. T. Campbell. 1979. Quasi-Experimentation. Boston: Houghton Mifflin.

Coakes, S. J., and L .G. Steed. 2003. SPSS Analysis without Anguish version 11 for Windows. Milton, QLD, Australia: John Wiley and Sons. 


\section{Ali-Effective Information Technology Governance Mechanisms}

De Haes, S., and W. V. Grembergen. 2005. IT governance structures, processes and relational mechanisms: Achieving IT/business alignment in a major Belgian Financial Group. Paper. Presented at the Proceedings of the 38th Hawaii International Conference on System Sciences.

Dehning, B., V. J. Richardson, and R. W. Zmud. 2003. The value relevance of announcements of transformational information technology investments. MIS Quarterly 27 (4): 637-656.

Doll, W. J. 1985. Avenues for Top Management Involvement in Successful MIS Department. MIS Quarterly 9 (1): 17-35.

Duffy, J. 2002. IT Governance and business value (part 1). IDC, nr. 27291.

Devaraj, S., and K. Rajiv. 2002. The IT Payoff. New York: Prentice Hall (Financial Times).

Earl, M. J. 1993. Experiences in strategic information systems planning. MIS Quarterly 17 (1): 1-24.

Goodhue, D. F., and J. L. King. 1991. Examining the computing and centralisation debate. Communication of the ACM 34 (7): 63-72.

Gorsuch, R. L. 1983. Factor Analysis. Hillsdale, N.J, Erlbaum.

Gormolski, B., J. Grigg, and K. Potter. 2001. 2001 IT spending and staffing survey results. Gartner R-14-4158.

Gottschalk, P. 1999. Implementation prediction of strategic information systems plan. Information and Management 36: 77-91.

Gujarati, D. 1999. Essentials of Econometrics (2 ${ }^{\text {nd }}$ ed.). Singapore: Irwin/McGraw-Hill.

Grembergen, W. V., S. De Haes, and E. Guldentops. 2004. Structures, processes and relational mechanisms for IT governance. In Grembergen (ed.), Strategies for Information Technology Governance: 1-36: Idea Group Publishing.

Grembergen, W. V., and S. De Haes. 2005. Measuring and improving IT governance through the balanced scorecard. Information Systems Control Journal 2: 35-42.

Hair, J. F., R. E. Anderson, R. L. Tatham, and W. C. Black. 1998. Multivariate Data Analysis ( (th $^{\text {th }}$ ed.). Upper Saddle River, NJ: Prentice Hall.

Haes, S. D., and W. V. Grembergen. 2004. IT governance and its mechanisms. Information Systems Control Journal 1.

Hardy, G. 2003. Coordinating IT governance-A new role for IT strategy committees. Information Systems Control Journal 4.

Henderson, J. C., N. Venkatraman, and S. Oldach. 1993. Continuous strategic alignment, exploiting information technology capabilities for competitive success. European Management Journal 11(2)..

Hewson, C., P. Yule, P., D. Laurent, and C. Vogel. 2003. Internet Research Methods: A Practical Guide for the Social and Behavioural Sciences. London: Sage Publication Ltd. 
Gadjah Mada International Journal of Business, January-April2006, Vol.8, No.1

IT Governance Institute. 2003a. Board briefing on IT governance. http://www.isaca.org/ Content/ContentGroups/ITGI3/Resources1/Board_Briefing_on_IT_Governance/ 26904_Board_Briefing_final.pdf. Visited 31 January 2005.

IT Governance Institute. 2003b. IT governance global status report. 2003. Http:// www.itgi.org/template_ITGI.cfm? Section=ITGIandCONTENTID= 14539andTEMPLATE=/ContentManagement/ContentDisplay.cfm. Visited 1 February 2005.

Jarvenpaa, S. L., and B. Ives. 1991. Executive involvement and participation in the management of information technology. MIS Quarterly 15 (2): 205-227.

Jiang, J. J., and G. Klein. 1999. Supervisor support and career anchor impact on the career satisfaction of the entry-level information system professional. Journal of Management Information Systems 16 (3): 219-240.

Karimi, J., A. Bhattacherjee, Y. P. Gupta, and T. M. Somers. 2000. The effect of MIS steering committees on information technology management sophistication. Journal of Management Information Systems 17 (2) (Fall): 207-230.

Kent, R., and M. Lee. 1999. Using the Internet for Market Research: A Study of Private Trading on the Internet. Journal of the Market Research Society 37(4): 377-389.

King, W.R. 1978. Strategic planning for management information systems. MIS Quarterly 2 (1): 27-37.

Luftman, J., and T. Brier. 1999. Achieving and sustaining business-IT alignment. California Management Review 42 (1): 109-122.

Luftman, J. 2000. Assessing business-IT alignment maturity. Communications of AIS 4.

McCabe, D.L., L. K. Trevino, and K. D. Butterfield. 1996. The influence of collegiate and corporate codes of conduct on ethics-related behavior in the workplace. Business Ethics Quarterly 6: 461-476.

McKeen, J. D., and T. Guimaraes. 1985. Selecting MIS projects by steering committee. Communications of the ACM 28 (12): 1344-1352.

Meyer, N. D. 2004. Systemic IS governance: An introduction. Information Systems Management 21 (4): 23-34.

Nath, R. 1989. Aligning MIS with the business goals. Information and Management 16: 71-79.

Nolan, R. L. 1982. Managing information systems by committee. Harvard Business Review: 72-79.

Nunnally, J. 1978. Psychometric Theory (2 ${ }^{\text {nd }}$ ed.). New York: McGraw-Hill.

Peterson, R. 2004. Crafting information technology governance. Information Systems Management 21 (4): 7-22.

Peterson, R. 2004. Information strategies and tactics for information technology governance. In Grembergen (ed.), Strategies for Information Technology Governance: Idea Group Publishing.

Premkumar, G., and W. R. King. 1994. The evaluation of strategic information system planning. Information and Management 26:327-340. 


\section{Ali-Effective Information Technology Governance Mechanisms}

Ragunathan, B., and B. Ragunathan. 1989. MIS steering committees: Their effect on information systems planning. Journal of Information Systems: 104-116.

Reich, B., and I. Benbasat. 2000. Alignment between business and IT objectives. MIS Quarterly 24(1): 81-113.

Rockart, J. F. 1988. The line takes the leadership. MIT Sloan Management Review 29 (Summer): 57-64.

Sambamurthy, V., and R. W. Zmud. 1999. Arrangements for information technology governance: A theory of multiple contingencies. MIS Quarterly 23 (1): 261-290.

Sampler, J., and P. Weill. 2003. Core incompetencies. Research Briefing III (1B).

Sabherwal, R. 1999. Therelationship between information system planning sophistication and information system success: An empirical assessment. Decision Sciences 30 (1): 137-167.

Salmela, H., A. L. Lederer, and T. Reponen. 2000. Information systems planning in a turbulent environment, European Journal of Information Systems 9(1): 3-15.

Schuman, S. P., and J. Rohrbaugh. 1991. Decision conference for systems planning. Information and Management 21: 147-159.

Schwartz, E. 2004. ?, Information Age: 48.

Sohal, A. S., and P. Fitzpatrick. 2002. IT governance and management in large Australian organisations. Int.J. Production Economics (75): 97-112.

Sohal, A. S., and L. Ng. 1998. The role and impact of information technology in Australian business. Journal of Information Technology 13: 201-217.

Stanton, J. M. 1998. An empirical assessment of data collection using the internet. Personnel Psychology 51 (3): 709-725.

Starre, D., and De Jong, B. 1998. IT Governance and Management:.Nolan, Norton and Co.

Steiner, G. A. 1979. Strategic Planning: What Every Manager Must Know. New York: Free Press.

Strauss, J. 1996. Early surveyresearch on the internet: Review, illustration and evaluation. In E.A. Blair and W.A. Kamakura (eds.), Proceedings of the American Marketing Association Winter Educators' Conference. Chicago: American Marketing Association.

Tabachnick, B. G., and L. S. Fidell. 1996. Using Multivariate Statistics $\left(4^{\text {th }}\right.$ ed. $)$ Needham Heights, MA: Allyn and Bacon.

Trevino, L. K., G. R. Weaver, D. G. Gibson, and B. L. Toffler. 1999. Managing ethics and legal compliance: What works and what hurts. California Management Review(41) (2) (Winter): 131-151.

Tse, A., K-C. Tse, Chow Hoi et al. 1995. Comparing two methods of sending out questionnaires: E-mail versus mail. Journal of the Market Research Society 37 (4): 441-447.

Van Der Zee, J.T.M., and B. De Jong. 1999. Alignment is not enough: Integrating business and information technology management with the balanced business scorecard. Journal of Information Systems 16 (2): 137-156. 
Gadjah Mada International Journal of Business, January-April 2006, Vol.8, No. 1

Van Grembergen, W., and R. Van Bruggen. 1997. Measuring and Improving Corporate Information Technology through the Balanced Scorecard Technique. Proceedings of the Fourth European Conference on the Evaluation of Information Technology, Delft.

Vaswani, R. 2003. Determinants of effective information technology (IT) governance. Unpublished Thesis. School of Business, University of Queensland, Australia.

Velicer, W. F., and J. L. Fava. 1998. Effects of variable and subject sampling on factor pattern recovery. Psychological Methods 3 (2): 231-251.

Weaver, G. R., Trevino, L. K., and P. L. Cochran. 1990. Corporate ethics practices in the mid-1990s: An empirical study of the fortune 1000. Journal of Business Ethics.

Weill, P. 2004. Don't just lead, govern: How top-performing firms govern IT. CISR Working Paper: CISR MIT.

Weill, P., and J. W. Ross. 2004. IT Governance: How Top Performers Manage IT Decision Rights for Superior Results. Boston, Massachusetts: Harvard Business School Press.

Woodhead, B. 2004. After the sky fell in on atlas. The Australian Financial Review: 36. 
Ali-Effective Information Technology Governance Mechanisms

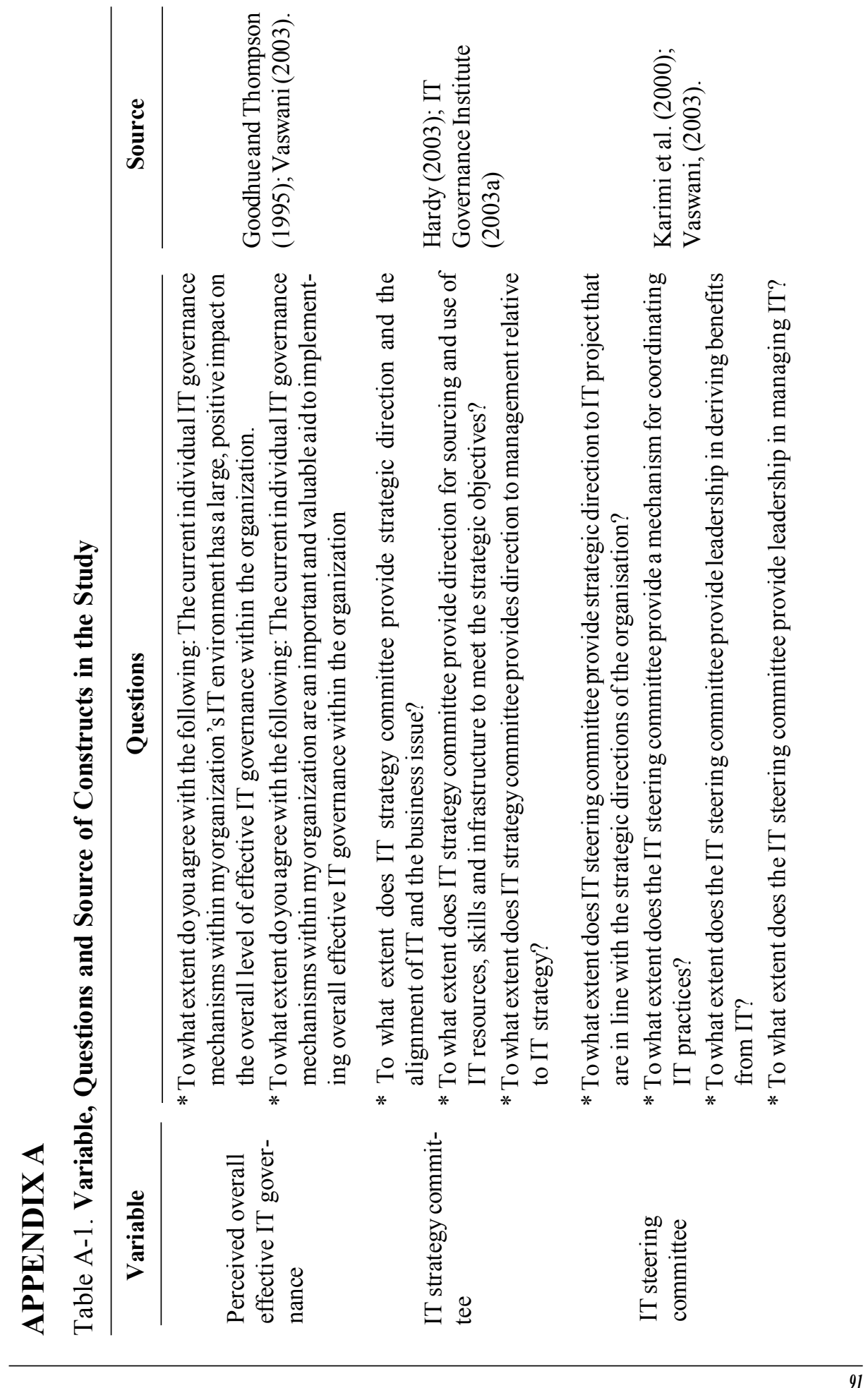


Gadjah Mada International Journal of Business, January-April 2006, Vol.8, No. 1

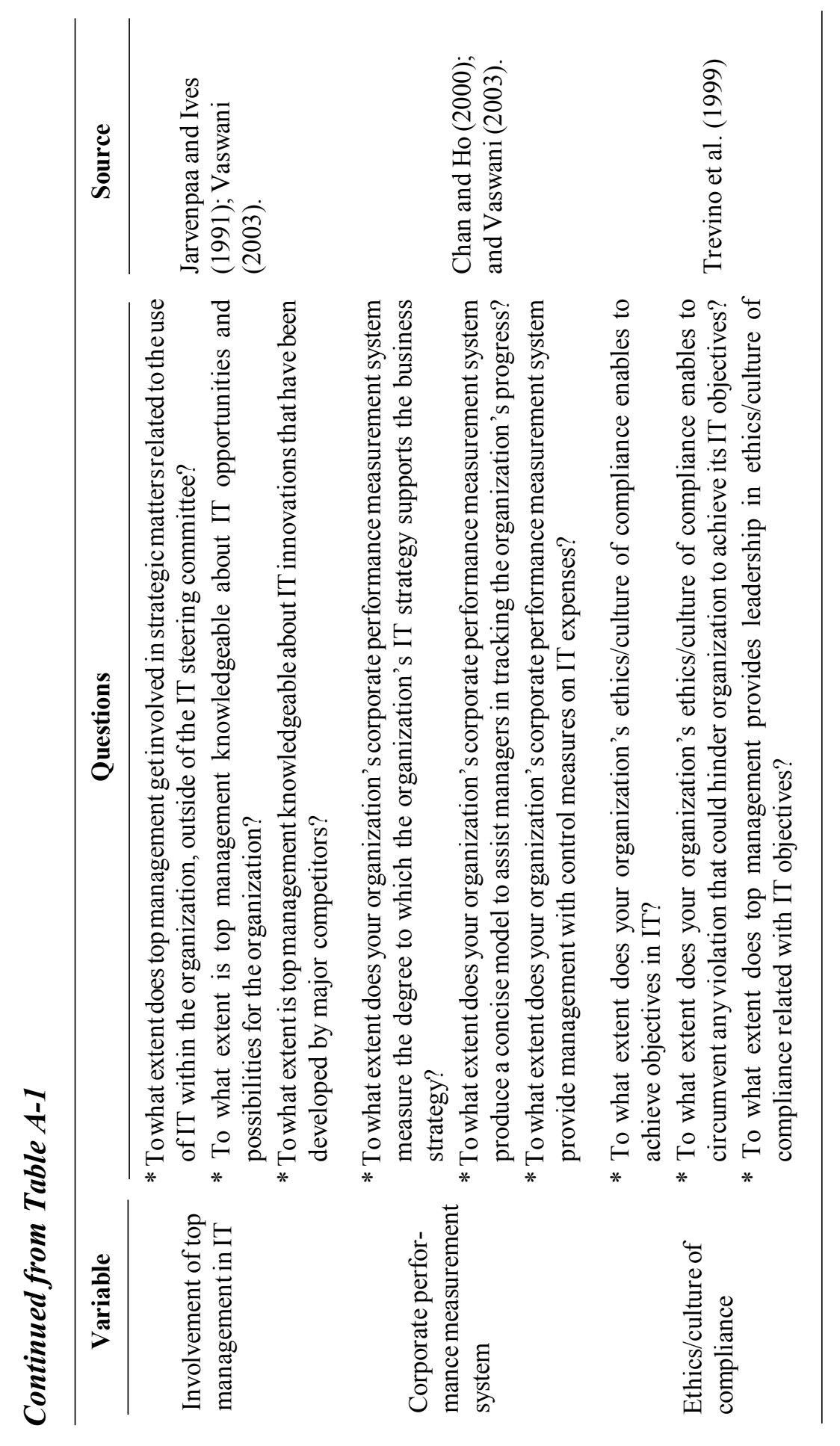


Ali-Effective Information Technology Governance Mechanisms

\section{APPENDIX B}

\section{Factors Analysis}

Factor analysis was performed to identify the structure of a set of variables in the survey data. In a similar manner to that of previous studies (Karimi, 2000; Vaswani, 2003; Coakes and Steed 2003; Clarkson et al. 2003), two separate factor analyses were conducted with an independent factor, and a dependent factor, effectiveness of IT governance.

\section{Data Examination}

Prior to factor analysis, the data should satisfy some statistical assumptions such as absence of outliers, normality, homoscedasticity, and linearity. A non-response bias test was also undertaken to establish the external validity of the sample data. Departures from these assumptions can diminish correlation between variables, resulting in a degradation of the factor analysis solution (Hair et al. 1998).

\section{Outliers}

As factor analysis is sensitive to the presence of outliers among cases and variables (Coakes and Steed 2003; Hair et al. 1998), data screening of the data set was undertaken prior to running the factor analysis. Any outliers and extreme scores identified in the data set were removed. ${ }^{\mathrm{a}}$

\section{Normality, homoscedasticity and linearity}

Normality is the most essential assumption in multivariate analysis (Hair et al. 1998). Although factor analysis is robust to breaches of assumptions of normality (Coakes and Steed 2003), the solution of a factor analysis is enhanced when variables are normally distributed. An examination of the skewness and kurtosis statistics from Table B-1, using box-plots and histogram graphs for the items, indicates that all items are reasonably distributed. To test linearity and homoscedasticity, an examination of the individual items was undertaken via scatter plots. The plots revealed no concerns in these areas.

\section{Non-response bias}

A non-response bias test was performed to establish the external validity of the data sample. External validity is concerned with the extent to which the results of a study can be generalised across a population (Cook and Campbell 1979). According to Armstrong and Overton (1977), if there are significant differences between participants and nonparticipants of a survey, its results are not sufficiently representative of the whole population.

To test the non-response bias, the sample was split into two subgroups following Jiang and Klein (1999). The first half of the sample are classified as early respondents and the

${ }^{a}$ Outliers were checked by inspection of $Z$-scores in which scores greater than +3 and less than -3 were considered to be outliers (Coakes and Steed 2003). 
Gadjah Mada International Journal of Business, January-April 2006, Vol. 8, No. 1

Table B-1. Descriptive Statistics — Factor Analysis

\begin{tabular}{|c|c|c|c|c|c|}
\hline Items* & Mean & Median & Std. Dev & Skewness & Kurtosis \\
\hline STRACOM1 & 4.8533 & 5.0000 & 1.82 & -0.792 & -0.371 \\
\hline STRACOM2 & 4.4595 & 5.0000 & 1.80 & -0.535 & -0.671 \\
\hline STRACOM3 & 4.7517 & 5.0000 & 1.80 & -0.727 & -0.430 \\
\hline STERCOM1 & 4.9451 & 5.0000 & 1.58 & -0.851 & 0.179 \\
\hline STERCOM2 & 4.5671 & 5.0000 & 1.62 & -0.535 & -0.386 \\
\hline STERCOM3 & 4.6380 & 5.0000 & 1.66 & -0.576 & -0.505 \\
\hline INVOLVE1 & 5.1839 & 5.5000 & 1.52 & -0.675 & -0.315 \\
\hline INVOLVE2 & 4.6000 & 5.0000 & 1.58 & -0.436 & -0.543 \\
\hline INVOLVE3 & 4.3886 & 4.0000 & 1.58 & -0.196 & -0.618 \\
\hline CORPSYS1 & 3.8802 & 4.0000 & 1.66 & -0.119 & -0.644 \\
\hline CORPSYS2 & 3.6766 & 4.0000 & 1.68 & -0.049 & -0.987 \\
\hline CORPSYS3 & 4.2544 & 4.0000 & 1.64 & -0.334 & -0.573 \\
\hline ETHICUL1 & 4.6364 & 5.0000 & 1.48 & -0.471 & -0.364 \\
\hline ETHICUL2 & 4.3486 & 5.0000 & 1.55 & -0.272 & -0.766 \\
\hline ETHICUL3 & 4.5000 & 5.0000 & 1.64 & -0.438 & -0.593 \\
\hline COMSYS1 & 4.5227 & 5.0000 & 1.59 & -0.413 & -0.596 \\
\hline COMSYS2 & 4.4091 & 4.0000 & 1.52 & -0.229 & -0.615 \\
\hline COMSYS3 & 4.1420 & 4.0000 & 1.64 & -0.269 & -0.689 \\
\hline EFFECT1 & 4.0568 & 4.0000 & 1.49 & -0.255 & -0.478 \\
\hline EFFECT2 & 4.2784 & 4.0000 & 1.48 & -0.308 & -0.402 \\
\hline
\end{tabular}

* All items were 7-point Likert Scales

other half are classified as late respondents. Independent group T-tests were undertaken across the items of the dependent variable and the six independent variables, to examine if there was a systematic difference between the means for the two sets of scores (early and laterespondents). The finding of a significant difference would imply a non-response bias. The results reveal that no significant differences exist between groups across all the variables items (Table B-6).

\section{Results of Factor Analysis}

\section{Independent Variables}

Hair et al (1998) suggests that factor analysis is not appropriate if the observations are fewer than 50, with 100 or more observation deemed preferable. They also provide a rule of thumb that the minimum sample size should have "at least five times as many observations as there are variables to be analyzed, and the more acceptable size would have a ten-to-one ratio" (Hair et al. 1998: 98-99). Given the sample size of this study is 176 cases, a 9.77 to 1 ratio, it was deemed appropriate to apply factor analysis.

In addition, for a matrix to be factorable, it should have several sizeable correlations greater than 0.30 (Tabachnick and Fidell 1996; Coakes and Steed 2003). An inspection of 
Ali-Effective Information Technology Governance Mechanisms

Table B-2. KMO and Bartlett's Test

\begin{tabular}{lcc}
\hline Kaiser-Meyer-Olkin Measure of Sampling Adequacy & 0.903 \\
\hline & Approx. Chi-Square & 2387.601 \\
Bartlett's Test of Sphericity & df & 153 \\
& Sig. & 0.000 \\
\hline
\end{tabular}

Table B-3. Total Variance Explained (EFA-First Run)

\begin{tabular}{|c|c|c|c|c|c|c|}
\hline \multirow[b]{2}{*}{ Component } & \multicolumn{3}{|c|}{ Initial Eigenvalues } & \multicolumn{3}{|c|}{$\begin{array}{c}\text { Extraction Sums of Squared } \\
\text { Loadings }\end{array}$} \\
\hline & Total & $\begin{array}{c}\% \text { of } \\
\text { Variance }\end{array}$ & $\begin{array}{c}\text { Cumulative } \\
\%\end{array}$ & Total & $\begin{array}{c}\% \text { of } \\
\text { Variance }\end{array}$ & $\begin{array}{c}\text { Cumulative } \\
\%\end{array}$ \\
\hline 1 & 9.459 & 52.549 & 52.549 & 9.459 & 52.549 & 52.549 \\
\hline 2 & 2.225 & 12.360 & 64.909 & 2.225 & 12.360 & 64.909 \\
\hline 3 & 1.389 & 7.714 & 72.623 & 1.389 & 7.714 & 72.623 \\
\hline 4 & 1.097 & 6.096 & 78.719 & 1.097 & 6.096 & 78.719 \\
\hline 5 & .817 & 4.539 & 83.258 & & & \\
\hline 6 & .553 & 3.070 & 86.328 & & & \\
\hline 7 & .405 & 2.248 & 88.576 & & & \\
\hline 8 & .331 & 1.836 & 90.412 & & & \\
\hline 9 & .280 & 1.553 & 91.965 & & & \\
\hline 10 & .263 & 1.462 & 93.427 & & & \\
\hline 11 & .253 & 1.404 & 94.831 & & & \\
\hline 12 & .191 & 1.059 & 95.890 & & & \\
\hline 13 & .169 & .936 & 96.826 & & & \\
\hline 14 & .164 & .911 & 97.737 & & & \\
\hline 15 & .129 & .717 & 98.454 & & & \\
\hline 16 & .116 & .643 & 99.097 & & & \\
\hline 17 & 8.396E-02 & .466 & 99.564 & & & \\
\hline 18 & $7.855 \mathrm{E}-02$ & .436 & 100.000 & & & \\
\hline
\end{tabular}

the Pearson correlation matrix indicates that more than 96 percent of the correlations exceed 0.30 , thus the matrix is suitable for factoring. The appropriateness of using factor analysis is further substantiated by Bartlett's test of Sphericity and the Kaiser-MeyerOlkin (KMO) measure of sampling adequacy. The Bartlett's test of Sphericity is significant at $\rho<0.001$ and the KMO measure of sampling $(0.903)$ is greater than 0.6 (Coakes and Steed 2003).

There are criteria for determining the adequacy and number of factors to extract. The most common way to estimate the number of factors is obtained from the size of the eigenvalues produced as part of a first run by principal component analysis (Tabachnick and Fidell 1996). An eigenvalue greater than one is considered significant and appropriate 
Gadjah Mada International Journal of Business, January-April 2006, Vol.8, No. 1

for further analysis (Hair et al. 1998). A total of four factors with eigenvalues greater than 1.0 were identified. These factors explained 78.7 percent of the total variance.

However, the eigenvalue criterion for establishing a cutoff is most preferable for numbers of variables between 20 and 50 (Hair et al, 1998). Thus, considering the situation, for this study an examination of the Scree test was undertaken as another way to determine the number of factors to extract (Catell 1966). Inspection of the Scree plot indicated that it would be more appropriate to extract six factors. This decision is supported by Gorsuch (1983) who contends "results from scree test are more obvious (and reliable) when sample size is large, communality values are high, and each factor has several variables with high loadings." ${ }^{\circ}$ Accordingly, the factor analysis was re-run, specifying that six factors were to be extracted.

The result of the six-factor extraction explained 86.3 percent of the total variance. During the second run of factor analysis, it was found that one of the compliance items, Ethics/Culture (ETHICUL3), cross-loaded on two factors instead of one distinct factor. ETHICUL3 was thus dropped and the analysis was re-run.

After the number of reliable factors became evident, the six factors were re-run once more using the Principal Component technique and rotated with an oblique rotation (i.e., Oblimin method). An oblique rotation was used because the underlying factors were believed to be correlated to a certain degree. The results indicates that requirements for construct validity (i.e., convergent and discriminant validity) have been satisfied, given that all items have a factor loading in excess of 0.6 , and less than 0.3 loading on all other constructs.

The factor structure was labeled subjectively, by inference from the nature of the grouped items. The first factor contains all three items relating to corporate communication systems and is labeled COMSYS. The second factor contains all three items relating to IT strategy committees and is labeled STRACOM. The third factor contains all three items relating to involvement of senior management in IT and is labeled INVOLVE. The fourth factor contains all three items relating to IT steering committees and is labeled STERCOM. The fifth factor contains all three items relating to corporate performance measurement systems and is labeled CORPSYS. The remaining two items relating to Ethics/Culture of compliance in IS are contained in ETHICUL. The results of the confirmatory factor analysis involving the final six factors. These factors explained 87.2 percent of the total variance.

\section{Dependent Variable (EFFECT)}

Table B-4. Factor Matrix-Dependent Variable

\begin{tabular}{lc}
\hline Variables & Component \\
\cline { 2 - 2 } & $\frac{1}{1}$ \\
EFFECT1 & 0.970 \\
EFFECT2 & 0.970 \\
\hline
\end{tabular}

${ }^{\mathrm{b}}$ All communality values of this study exceed 0.6 . 


\section{Ali-Effective Information TechnologyGovernance Mechanisms}

The separate factor analysis performed on the items relating to the dependent variable (perceived overall effectiveness of IT governance) indicates only one factor, which is then labelled as EFFECT.

\section{Reliability Measurement}

Subsequent to the prior three factor analyses, a reliability test was performed for the extracted factors. None of the factors' alpha is lower than 0.6. Consequently, these factors provide a reliable and consistent measure of intended dimension and no further exclusion of variables appears necessary.

Table B-5. Reliability Calculations (Cronbach's Alpha)

\begin{tabular}{|c|c|c|}
\hline No & Variable & Reliability* \\
\hline 1. & Overall effectiveness of IT governance & 0.9379 \\
\hline 2. & IT strategy committee & 0.9267 \\
\hline 3. & IT steering committee & 0.9070 \\
\hline 4. & Involvement of top management in IT & 0.8915 \\
\hline 5. & Corporate performance measurement system & 0.9067 \\
\hline 6. & Ethics/Culture of compliance & 0.8955 \\
\hline 7. & Corporate communication systems & 0.9537 \\
\hline
\end{tabular}

*Reliability measure is Cronbach's Alpha 
Gadjah Mada International Journal of Business, January-April 2006, Vol. 8, No. 1

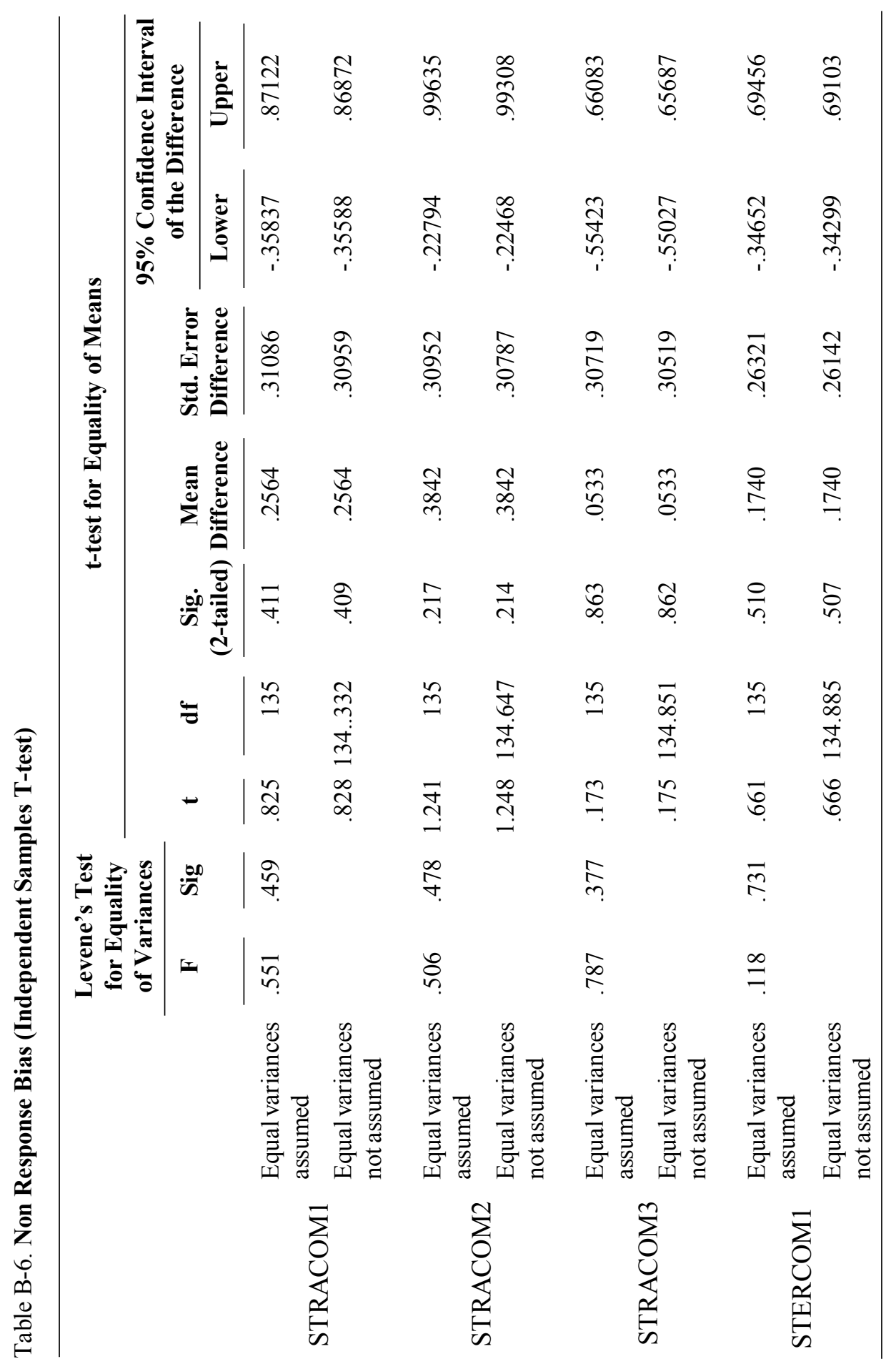


Ali-Effective Information Technology Governance Mechanisms

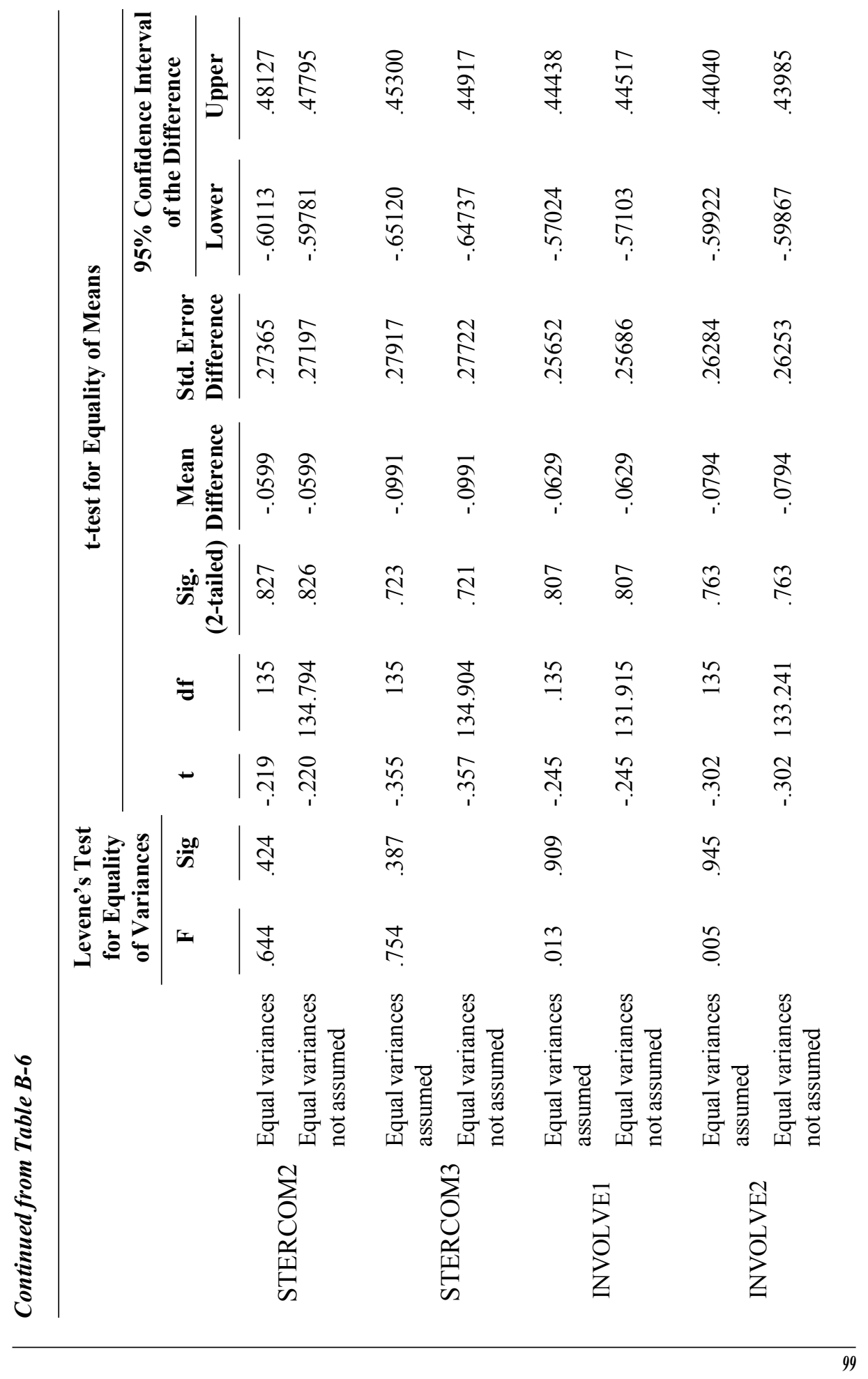


Gadjah Mada International Journal of Business, January-April 2006, Vol.8, No. 1

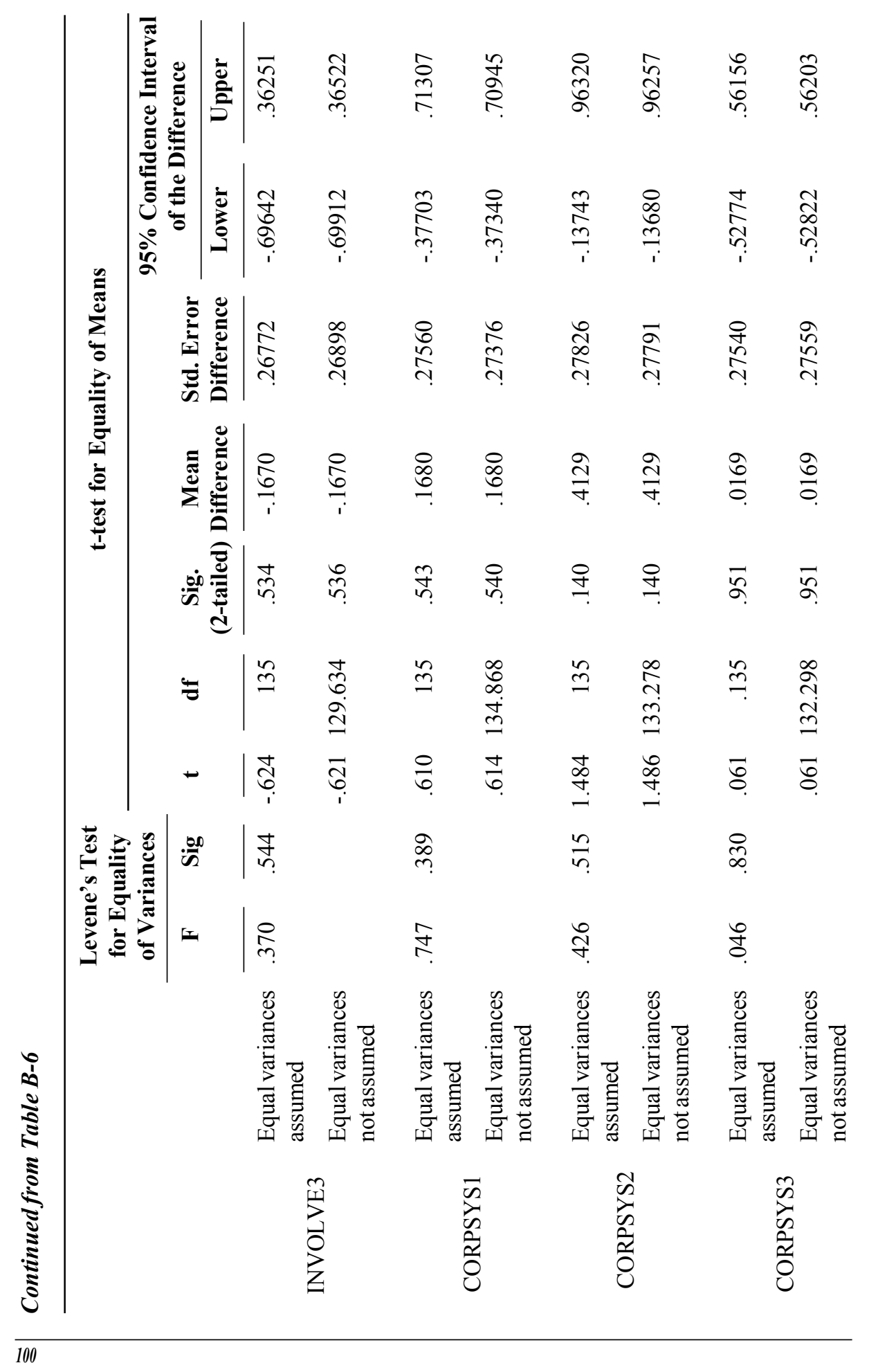


Ali-Effective Information Technology Governance Mechanisms

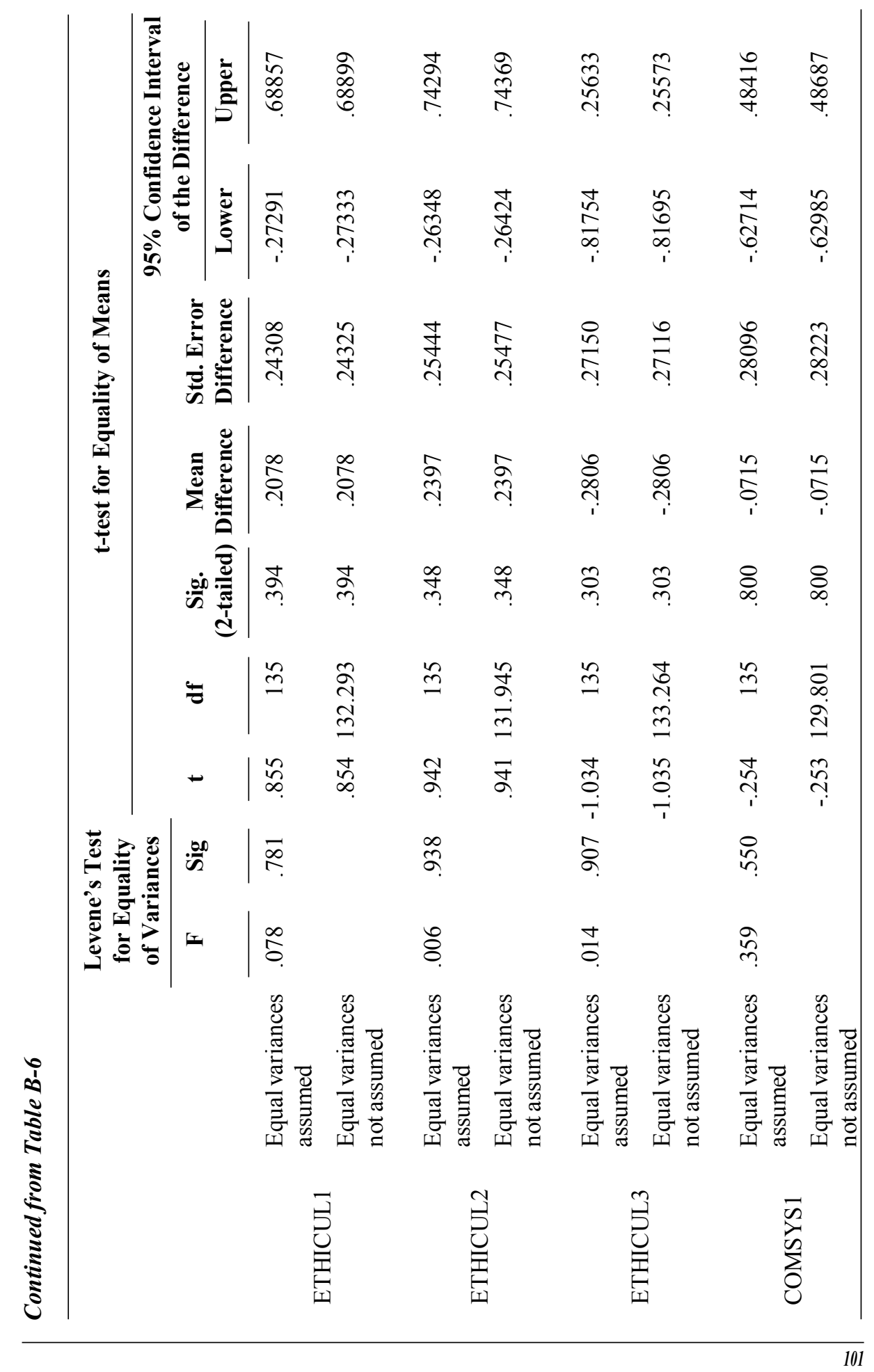


Gadjah Mada International Journal of Business, January-April 2006, Vol. 8, No. 1

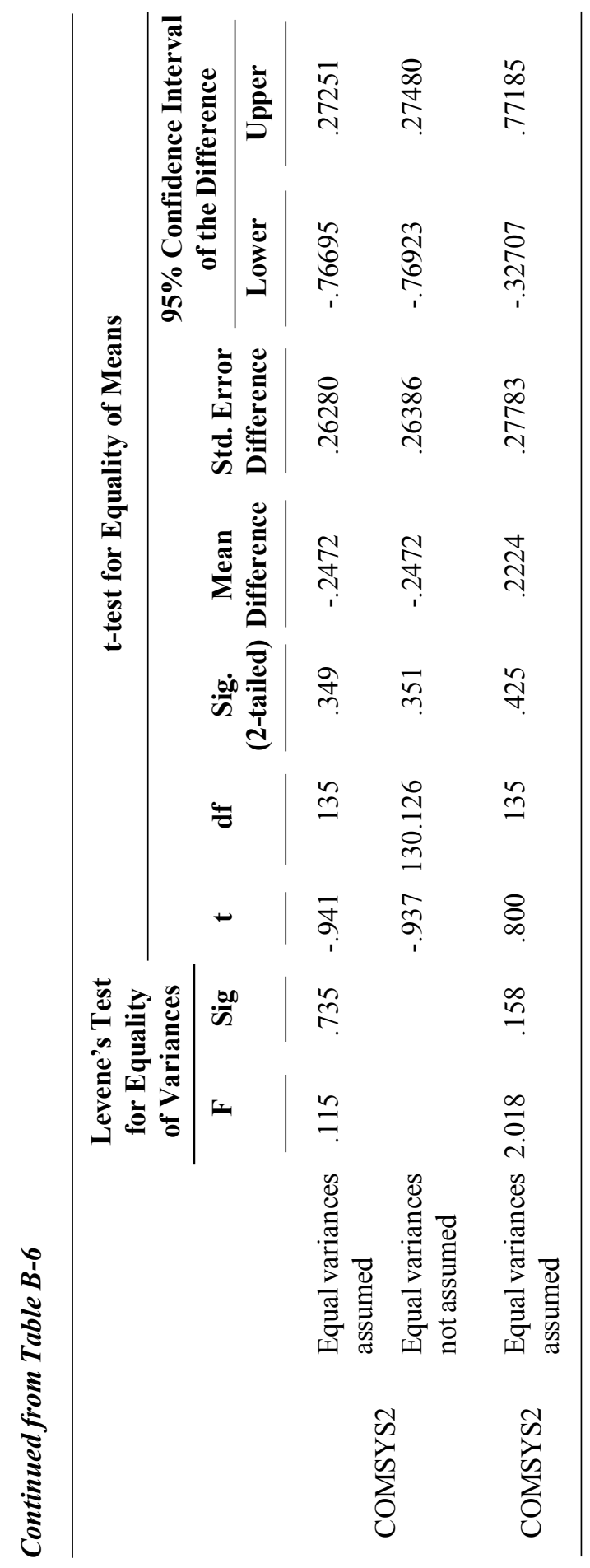

